\title{
Komunikasi Persuasif dalam Kampanye Gerakan Anti Hoaks oleh Komunitas Mafindo Jakarta
}

\author{
Asyffa Nauma Dilla, Diah Ayu Candraningrum \\ asyffa.915150151@stu.untar.ac.id,diahc@fikom.untar.ac.id \\ Fakultas Ilmu Komunikasi Universitas Tarumanagara
}

\begin{abstract}
Mafindo (Anti-Defamation Society of Indonesia) is an independent community movement that deals with public literacy and education regarding hoaxes. Mafindo community was established to minimize the spread of hoaxes on social media. The purpose of this study was to study persuasive communication in the anti-hoax movement campaign on digital literacy training "Without Hoax, We Get Together in Democracy" conducted by the Mafindo community in the context of community movements towards hoaxes. This research was conducted using qualitative descriptive research with case study research methods. Data collection techniques used were interviews, observation, library research, and documentation. The theory used in this study is the Campaign Theory, Persuasive Communication Theory and the Stages of Change Theory. The results of this study indicate that the Anti-Hoax Movement Campaign conducted by Mafindo community has the concept of education and socialization which is packaged in 2 forms namely online through social media and offline through digital literacy training. Persuasive communication that is applied meets the elements of Claim, Warrant and Data and the Persuasive Technique that is carried out by applying the Association Technique, is the presentation of messages that are displayed attractively so as to form public attention.
\end{abstract}

Keywords : Campaign, Persuasive Communication, Hoax, Stages of Change Theory

\begin{abstract}
Abstrak
Mafindo (Masyarakat Anti Fitnah Indonesia) merupakan gerakan komunitas independen yang berkenaan dengan literasi dan edukasi masyarakat mengenai hoaks. Komunitas Mafindo didirikan untuk meminimalisasi penyebaran berita bohong (hoaks) pada media sosial. Tujuan penelitian ini adalah untuk mempelajari komunikasi persuasif dalam kampanye gerakan anti hoaks pada kegiatan pelatihan literasi digital "Tanpa Hoaks, Kita Rukun Berdemokrasi" yang dilakukan komunitas Mafindo dalam konteks pergerakan masyarakat terhadap hoaks. Penelitian ini dilakukan dengan menggunakan penelitian deskriptif kualitatif dengan metode penelitian studi kasus. Teknik pengumpulan data yang digunakan adalah wawancara, observasi, studi kepustakaan dan dokumentasi. Teori yang digunakan dalam penelitian ini adalah Teori Kampanye, Teori Komunikasi Persuasif dan Teori Tahapan Perubahan. Hasil dari penelitian ini menunjukan bahwa Kampanye Gerakan Anti Hoaks yang dilakukan Komunitas Mafindo memiliki konsep edukasi dan sosialisasi yang dikemas dalam dua bentuk yakni online melalui media sosial dan offline melalui pelatihan literasi digital. Komunikasi persuasif yang diterapkan memenuhi unsur Claim Warrant dan Data serta Teknik Persuasif yang dilakukan yaitu dengan penerapan Teknik Asosiasi, merupakan penyajian pesan yang ditampilkan secara menarik sehingga membentuk perhatian publik.
\end{abstract}

Kata Kunci: Kampanye, Komunikasi Persuasif, Hoaks, Teori Tahapan Perubahan Perilaku 


\section{Pendahuluan}

Kehadiran teknologi yang semakin modern, memberikan kemudahan masyarakat dalam mengakses berbagai jenis informasi. Menurut Kaplan dan M. Haenlein (2010:60), media sosial merupakan sebuah aplikasi berbasis internet dengan sebuah layanan web 2.0 yang memungkinkan pengguna berbagi aneka konten. Sedangkan menurut McQuail (2012:148), media baru tercipta karena adanya proses digitalisasi teknologi, yang mengubah fungsi internet sehingga dapat digunakan menjadi alat komunikasi pribadi. Kematangan teknologi mempermudah dalam berkomunikasi, namun kemudahan berbagi informasi dengan bantuan teknologi yang ada, menimbulkan kemungkinan jika informasi yang tersebar melalui media sosial menjadi dipertanyakan keakuratannya yaitu memunculkan istilah hoaks atau berita bohong (https://kbbi.kemdikbud.go.id/entri/hoaks, diakses pada 23 Februari 2019 pukul 19.00 WIB).

Hasil survei yang dilakukan oleh Masyarakat Telematika Indonesia (MASTEL) menunjukkan, secara daring terhadap 1.116 responden pada 7 - 8 Februari 2017 lalu, menyatakan bahwa jenis hoaks yang persentasenya paling besar beredar pada masyarakat adalah hoaks mengenai sosial politik sebesar $91.8 \%$. (https://mastel.id/infografis-hasil-survey-mastel-tentang-wabah-hoax-nasional/ diakses pada 8 Maret 2019 pukul 19.30 WIB). Semakin meningkatnya penyebaran berita bohong (hoaks), khususnya hoaks mengenai sosial politik, didukung dengan kemajuan teknologi yang ada, menjadikan terbentuknya beberapa komunitas yang menyuarakan penolakan terhadap hoaks.

Salah satu komunitas tersebut adalah Masyarakat Anti Fitnah Indonesia (Mafindo), merupakan organisasi masyarakat sipil yang didirikan pada tanggal 19 November 2016, namun sudah aktif melakukan penolakan terhadap hoaks sejak 2015 lalu. Komunitas Mafindo telah mempelopori banyak inisiatif anti hoaks. Komunikasi yang diterapkan Komunitas Mafindo (Masyarakat Anti Fitnah Indonesia) bertujuan untuk meningkatkan kesadaran masyarakat, serta pengetahuan tiap individu dalam memfilter berbagai informasi yang belum pasti kebenarannya (https://www.mafindo.or.id/about/, diakses pada 8 Maret 2019 pukul 19.00 WIB).

Berdasarkan latar belakang masalah tersebut, penelitian ini berfokus kepada "bagaimana komunikasi persuasif dalam kampanye gerakan anti hoaks pada kegiatan pelatihan literasi digital 'Tanpa Hoaks, Kita Rukun Berdemokrasi' yang dilakukan Komunitas Mafindo dalam upaya mengubah perilaku masyarakat terhadap hoaks?". Tujuan penelitia ini yaitu untuk mengetahui bagaimana komunikasi persuasif dalam kampanye gerakan anti hoaks pada kegiatan pelatihan literasi digital "Tanpa Hoaks, Kita Rukun Berdemokrasi” yang dilakukan Komunitas Mafindo dalam upaya mengubah perilaku masyarakat terhadap hoaks.

\section{Metode Penelitian}

Dalam penelitian ini, peneliti menggunakan pendekatan penelitian kualitatif deskriptif dengan metode penelitian studi kasus. Pendekatan kualitatif deskriptif dan metode studi kasus digunakan untuk memahami fenomena, mendapatkan gambaran secara utuh, faktual, dan sistematis mengenai komunikasi persuasif dalam suatu program kampanye Anti Hoaks dari Komunitas Mafindo Jakarta, melalui deskripsi uraian yang dialami oleh subjek penelitian Menurut Cresswell (dalam Herdiansyah, 2010:76) studi kasus merupakan suatu teknik yang menekankan pada eksplorasi dari 
suatu sistem yang terbatas (bounded system), pada sebuah kasus atau beberapa kasus secara mendetail, disertai dengan penggalian data secara mendalam yang melibatkan beragam sumber informasi yang kaya akan konteks.

Subyek penelitian dalam penelitian ini terdapat dua jenis yaitu key informant dan informan lainnya sebagai pendukung. Narasumber yang menjadi key informant diantaranya yaitu Direktur Operasional Komunitas Mafindo Pusat dan salah satu Tim edukasi Mafindo. Informan pendukung dalam penelitian ini yaitu beberapa individu yang menjadi audiens pada kegiatan edukasi yang diadakan oleh Komunitas Mafindo. Adapun obyek dalam penelitian ini adalah penerapan komunikasi persuasif dalam kampanye gerakan anti hoaks pada kegiatan pelatihan literasi digital yang dilakukan komunitas Mafindo dalam upaya mengubah perilaku masyarakat terhadap hoaks.

Metode pengumpulan data yang dilakukan antara lain melalui data primer dan sekunder. Dalam data primer, peneliti menggunakan metode wawancara terstruktur langsung dengan informan melalui pedoman wawancara, dan menggunakan metode observasi partisipan, dimana peneliti ikut serta dalam kegiatan yang berkaitan dengan gerakan anti hoaks yang diadakan oleh Komunitas Mafindo untuk melengkapi informasi dalam penelitian yang akan dilakukan peneliti. Peneliti juga menggunakan data sekunder melalui dokumentasi dan studi kepustakaan untuk melengkapi informasi seputar penulisan penelitian ini secara utuh.

Teknik pengolahan data dalam penelitian ini menggunakan teknik reduksi data, penyajian data dan penarikan kesimpulan atau verifikasi data. untuk memaksimalkan hasil dari sebuah penelitian yang akan dilakukan peneliti, uji keabsahan data diperlukan agar data dan informasi yang diperoleh dapat dipertanggungjawabkan secara ilmiah. Teknik keabsahan data yang dipergunakan peneliti dalam penelitian ini ialah teknik triangulasi. Teknik triangulasi merupakan sebuah teknik mengukur keabsahan data yang dilakukan oleh peneliti, bertujuan untuk perbandingan terhadap hasil dari data penelitian, dengan memanfaatkan berbagai data lainnya sehingga data dan informasi yang diperoleh peneliti merupakan data dan informasi yang valid (Moleong, 2012:330).

\section{Hasil Temuan dan Pembahasan}

Pesta demokrasi pemilihan presiden, legislatif dan perwakilan daerah pada 17 April 2019 lalu, menimbulkan kekhawatiran terhadap penyebaran hoaks terkait politik akan semakin masif dan berpotensi menimbulkan perpecahan di masyarakat. Hoaks menjadi ancaman serius yang bisa mempengaruhi dinamika sosial. Demi mengatasi penyebaran berita bohong di media sosial ini, Komunitas Mafindo mengusung sebuah Kampanye Gerakan Anti Hoaks sesuai taglinenya "Turn Back Hoax", yang bertujuan untuk menjaga kerukunan antar elemen bangsa, mengajak masyarakat untuk cerdas bermedia sosial dan melibatkan masyarakat untuk berpartisipasi membersihkan media sosial dari hoaks yang memprovokasi.

Mafindo adalah sebuah gerakan komunitas yang peduli terhadap literasi digital dan edukasi masyarakat tentang hoaks. Mafindo didirikan bertujuan untuk meminimalisasi penyebaran berita bohong (hoaks) di dunia maya. Mafindo bergerak secara independen, tidak memihak kepada afiliasi politik atau kelompok manapun, murni berlandaskan gerakan moral menghimpun masyarakat tanpa melihat preferensi SARA, dan berpegang teguh kepada fakta.

Dalam rangka mewujudkan program Kampanye Gerakan Anti Hoaks tersebut, salah satu upaya yang Mafindo lakukan ialah secara aktif menyelenggarakan kegiatan 
mengenai literasi digital kepada seluruh lapisan masyarakat. Kegiatan mengenai literasi digital kali ini bertemakan "Tanpa Hoaks, Kita Rukun Berdemokrasi”. Acara ini diselenggarakan oleh relawan Mafindo pada hari Sabtu, 13 April 2019 pukul 09.30 sampai 15.30 WIB, bertempat di Ruang Rapat Hotel Bumi Wiyata, Depok.

Mafindo sebagai komunikator atau persuader yang bergerak secara mandiri, sebagai organisasi non-profit memiliki visi misi untuk mengedukasi masyarakat, dengan cara yang sederhana agar mereka tidak terjebak hoaks. Mafindo mengemas program Kampanye Gerakan Anti Hoaks melalui kegiatan edukasi-sosialisasi yang diadakan secara online (di media sosial) dan offline (melalui kegiatan pelatihan secara langsung). Melalui program kampanye ini, Mafindo berharap masyarakat bisa sadar, peduli dan mengubah perilaku bermedianya menjadi lebih bijak dan mindfulness.

Menurut Rogers dan Storey (dalam Venus, 2004:7), kampanye adalah serangkaian kegiatan komunikasi yang terorganisir dengan tujuan menciptakan dampak tertentu terhadap sebagian besar khalayak sasaran secara berkelanjutan dalam periode waktu tertentu. Pelaksanaan sebuah kampanye tidak terlepas dari unsur persuasif dalam komunikasi persuasif. Komunikasi persuasif dapat diartikan sebagai komunikasi yang memiliki tujuan mengubah atau memengaruhi kepercayaan, sikap dan perilaku seseorang sehingga bertindak sesuai dengan yang diharapkan oleh komunikator. (Devito, 2013:62).

Kampanye termasuk ke dalam praktik persuasif maka dari itu teori kampanye banyak mengadopsi teori komunikasi persuasif. Hal ini didukung oleh pendapat Michael Pfau \& Roxanne Parrot (dalam Ruslan, 2013:26) bahwa, campaign are inherently persuasive communication activities, artinya aktivitas kampanye selalu melekat dengan kegiatan komunikasi persuasif yang bertitik pada tindakan komunikasi persuasif pada lingkup yang luas. Tindakan persuasif menjadi unsur vital untuk mewujudkan pesan kampanye yang ingin dibentuk.

Berdasarkan pembagian jenis kampanyenya, kampanye Gerakan Anti Hoaks yang Mafindo lakukan termasuk pada jenis Ideological or Cause - Orientated Campaign yang bertujuan pada perubahan sosial (Social Change Campaign) dan bersifat non komersial (Larson dalam Ruslan, 2013:25). Hal ini dapat dilihat dari cara Mafindo dalam menyelenggarakan acaranya. Mafindo salah satu kegiatan offlinenya gemar menggelar kegiatan edukasi-sosialisasi mengenai literasi digital dan hoaks tanpa dipungut biaya.

Komunikasi persuasif yang dilakukan Mafindo sebagai komunikator menjadi penentu bagaimana pesan kampanye tersebut bisa diterima, dimengerti dan dilakukan oleh komunikan atau persuadee yaitu audiens kegiatan edukasi-sosialisasi. Sesuai dengan unsur persuasif yang diungkapkan Maulana \& Gumelar (2013:8) terdapat tiga aspek yang harus dipenuhi dalam sebuah pesan kampanye persuasif yakni: claim, warrant dan data. Dalam claim atau pemaparan tujuan persuasi, Mafindo dalam kampanyenya, offline maupun online, selalu memaparkan secara tersurat program kampanye anti hoaks yang sedang mereka lakukan. Begitu juga dalam pelaksanaanya (warrant), Mafindo tidak pernah memaksa memerintah secara keras kepada audiens yang hadir dalam kegiatan edukasi-sosialisasi untuk patuh mengikuti apa yang mereka sampaikan. Pendekatan yang dilakukan lebih halus serta perintah yang diberikan bersifat ajakan dan bujukan. Di setiap pelaksanaan kegiatan edukasi-sosialisasi, Mafindo menampilkan konten-konten menarik dan informatif yang dihimpun melalui riset sebelumnya (data), jadi dapat dipastikan fakta atau informasi yang mereka tampilkan adalah valid. 
Apabila dilihat dari medianya, Mafindo melakukan edukasi-sosialisasi melalui media online dan offline. Melalui media online, Mafindo memiliki halaman facebook utama yang biasa digunakan untuk menyebarkan klarifikasi mengenai berita hoaks yang beredar. Melalui halaman Facebook ini juga masyarakat bisa memperbarui informasi seputar kegiatan offline yang diselenggarakan Mafindo. Selain itu ada pula grup Forum Anti Fitnah, Hasut dan Hoax yang Mafindo sediakan untuk publik yang ingin berdiskusi atau berkontribusi dalam pencarian informasi seputar hoaks. Publik bisa secara sukarela memberi klarifikasi apabila ada berita yang mereka temukan diluar sana termasuk kedalam kategori hoaks.

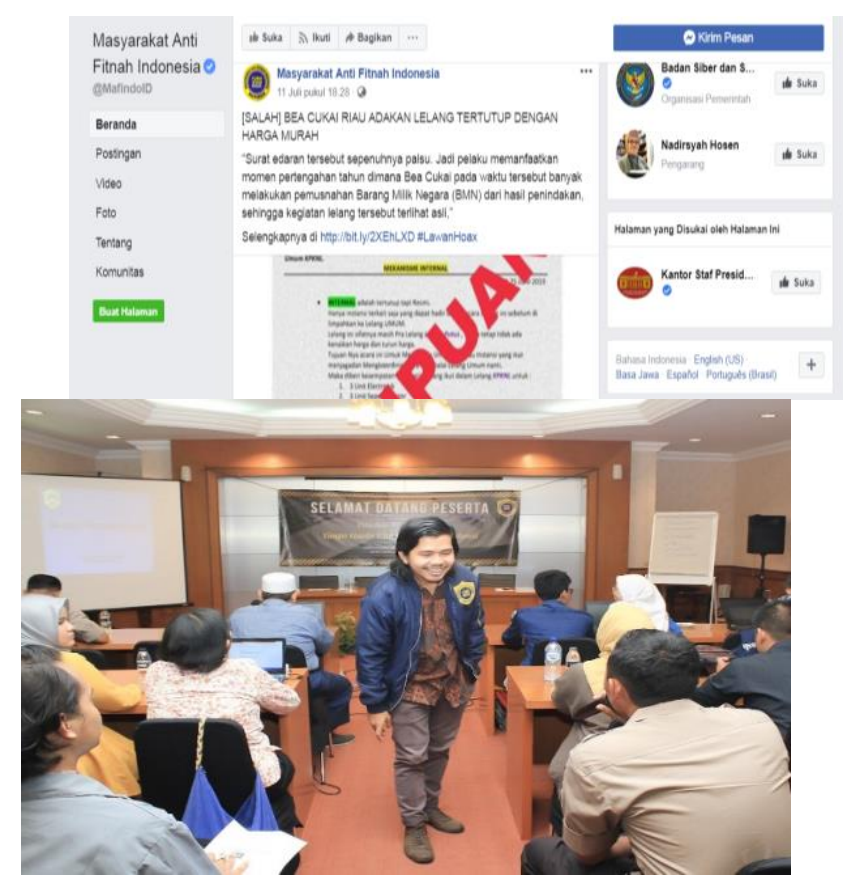

Gambar 1. Kampanye online dan offline Komunitas Mafindo

(Sumber : https://www.facebook.com/MafindoID/, diakses pada tanggal 14 Juli 2019 pukul 16.50 WIB dan Dokumentasi Komunitas Mafindo)

Selanjutnya adalah kampanye secara offline yaitu edukasi-sosialisasi secara tatap muka langsung yang rutin dilakukan melalui kegiatan mengenai literasi digital berbasis edukasi-sosialisasi. Melalui kegiatan literasi digital berbasis edukasisosialisasi secara tatap muka, Mafindo berusaha mengajak audiens secara perlahan kedalam materi yang mereka sampaikan sehingga pemahaman itu sampai kepada cara berpikir mereka untuk lebih peduli akan keadaan media sosial yang sudah tidak sehat. Mafindo juga mengajarkan secara langsung berbagai cara mengidentifikasi dan melaporkan hoaks menggunakan aplikasi resmi yang Mafindo miliki bernama "Hoax Buster Tools". Sebuah berita yang masuk akan diidentifikasi mulai dari judul, gambar dan narasi apakah sesuai fakta. Kemudian dari sini audiens diarahkan untuk bisa mempraktekannya dengan mengcopy link berita asli tersebut untuk disebarkan di platform manapun kepada orang lain, agar orang lain bisa mengakses berita sebenarnya (sumber: hasil wawancara bersama Dewi Sartika Sari, 15 Mei 2019).

Dilihat dari media yang digunakan Mafindo untuk menyebarkan kampanyenya, dalam persuasif teknik ini termasuk kepada teknik asosiatif. Teknik asosiatif juga menyajikan pesan komunikasi dengan cara menumpahkannya pada suatu obyek atau peristiwa yang sedang menarik perhatian khalayak (Effendy, 2004: 23). Mafindo 
berusaha selembut mungkin membujuk audiens untuk membangkitkan rasa kepeduliannya. Salah satunya dengan menggali pengalaman sehari-hari audiens dan membuat hal tersebut menjadi obyek sebagai upaya untuk mempengaruhi pola pikir masyarakat. (Sumber: hasil wawancara bersama Heni Mulyati, 15 Mei 2019).

Dari pelaksanaan program kampanye yang berjalan menunjukan bahwa Kampanye Gerakan Anti Hoaks yang Mafindo lakukan sesuai dengan 5 tujuan kampanye sebagaimana yang diungkapkan oleh Ruslan (2013:96-97) yaitu: public awareness, offer information, public education, reinforces the attitude and behaviour serta behaviour modification.

Hal ini didukung sebagaimana yang diungkapkan oleh key informant Dewi, bahwa tidak hanya menyelenggarakan acara edukasi atau membuat konten edukasi dipublik, Mafindo justru sering diundang untuk mengisi kegiatan edukasi terkait hoaks, oleh beberapa pihak. Artinya hal tersebut merupakan timbal balik yang positif, yang tersebar dari mulut ke mulut dan memiliki kontribusi terhadap upaya mengedukasi audiens manapun dalam meminimalisasi penyebaran hoaks.

\section{Stages of Change Theory}

Dalam kampanye komunikasi persuasif yang dilakukan, aspek perubahan perilaku menjadi komponen efek tatanan komunikasi. Hal ini sebagaimana yang diterapkan Mafindo dalam mengevaluasi kegiatan mereka. Sebelum dan setelah kegiatan edukasi-sosialisasi, Mafindo memberikan form pre test dan form post test untuk mengukur apakah peserta memahami materi yang disampaikan, dari situ mereka bisa menilai sejauh mana pemahaman sebelum dan sesudah kegiatan edukasisosialisasi pada audiens yang hadir.

Menurut Venus (2004:39-40), Stages of Change Theory sangat membantu menganalisis dan menguraikan sejauh mana kampanye berjalan serta untuk menggambarkan pengalaman yang dialami dari sisi audiens secara bertahap. Terdapat 5 Tahap diantaranya yaitu:

Tahap pertama yaitu precontemplation (praperenungan), pada tahap ini masalah sosial mulai muncul namun khalayak belum bersimpati pada permasalahan. Di tahap ini banyak dari audiens yang belum sadar bahwa hoaks adalah suatu ancaman. Tahap kedua yaitu contemplation (perenungan), pada tahap ini audiens sadar mengenai keberadaan hoaks dan kemudian mendapat dorongan untuk berpikir mengenai perlunya melakukan sebuah tindakan. Disinilah kampanye gerakan anti hoaks yang Mafindo lakukan perlahan - lahan terdengar ke telinga audiens dan menarik simpatik untuk mempelajarinya lebih dalam. Pada tahap ini Mafindo berupaya memanipulasi cara berpikir audiens mengenai berbagai macam keuntungan dan kerugian yang bisa diperoleh dalam bermedia sosial. Pemahaman ini mereka tularkan melalui konten konten di facebook milik Mafindo khususnya bagi publik yang belum mengenal Mafindo untuk menarik audiens bersama-sama bergabung melawan hoaks dan menghadiri kegiatan edukasi-sosialisasi anti hoaks. Di tahap ini juga edukasi mengenai hoaks mulai sedikit diperkenalkan.

Tahap berikutnya yaitu preparation (persiapan) yaitu tahap ketika mereka mengambil sebuah keputusan bahwa dirinya harus melakukan suatu tindakan berubah. Persiapannya ditandai dengan komitmen mereka untuk mengikuti program edukasisosialisasi mengenai literasi digital Kampanye Anti Hoaks ini. Tahap selanjutnya keempat yaitu action (tindakan). Di tahap ini perubahan perilaku audiens pasca mengikuti kegiatan literasi dalam rangka Kampanye Gerakan Anti Hoaks akan terlihat. Pada tahap ini terlihat bahwa pola pikir audiens berubah mengenai cara mengahadapi 
pemberitaan yang ia terima dari media sosial dan audiens lebih teredukasi mengenai cara mengidentifikasi hoaks dan cara mengklarifikasinya dengan tindakan think before sharing yang selalu diterapkan.

Tahap kelima yaitu maintenance (pemeliharaan). Di tahap ini konsistensi perubahan audiens akan menjadi evaluasi bagi Mafindo karena menyangkut penilaian apakah kampanye berlangsung sesuai target atau tidak. Audiens menunjukan cara berpikir mereka sudah jauh lebih maju untuk menghadapi hoaks. Audiens tidak ragu untuk menegur, melaporkan apabila ada hoaks disekitar mereka. Mereka bahkan berkontribusi mengajak dan mengedukasi anggota keluarga dan teman lainnya untuk belajar mengenai hoaks. Peneliti melihat bahwa melalui Stages of Change Theory di atas, secara tidak langsung didalamnya sudah terdapat pendekatan persuasif yang selama ini terjadi.

\section{Simpulan}

Komunikasi persuasif yang Mafindo lakukan dalam upaya meminimalisasi penyebaran hoaks bahwa Kampanye Gerakan Anti Hoaks yang dilakukan Mafindo memiliki konsep edukasi dan sosialisasi yang dikemas dalam dua bentuk yakni online melalui media sosial dan offline melalui kegiatan literasi digital dan anti hoaks. Komunikasi persuasif dalam praktik kampanye gerakan anti hoaks melalui kegiatan literasi digital dan anti hoaks yang diterapkan Mafindo memiliki ketiga unsur dalam komunikasi persuasif seperti claim. Komunitas Mafindo pada saat kampanyenya baik offline maupun online selalu memaparkan secara tersurat program kampanye anti hoaks yang sedang mereka lakukan.

Pada saat pelaksanaannya (Warrant), Komunitas Mafindo tidak pernah memaksa memerintah secara keras kepada audiens yang hadir dalam kegiatannya untuk patuh mengikuti apa yang mereka sampaikan, pendekatan yang dilakukan lebih halus serta perintah yang diberikan bersifat ajakan dan bujukan. Pada setiap kegiatan edukasi-sosialisasinya, Komunitas Mafindo menampilkan konten - konten menarik dan informatif yang dihimpun melalui riset sebelumnya (Data). Pengalaman dari sisi audiens pasca kegiatan edukasi-sosialisasi dapat diidentifikasi melalui Stage of Change Theory yang terdiri dari lima tahap yaitu Praperenungan, Perenungan, Persiapan, Tindakan, dan Pemeliharaan.

\section{Ucapan Terima Kasih}

Penelitian ini terwujud atas bantuan dari Pengurus Komunitas Mafindo Jakarta dan peserta kegiatan edukasi-sosialisasi mengenai literasi digital dan anti hoaks, yang telah memberikan kesempatan dan waktunya kepada peneliti untuk melakukan penelitian sehingga laporan skripsi ini bisa terselesaikan tepat waktu. Rasa terimakasih yang sebesar - besarnya juga ditujukan kepada Ibu Diah Ayu Candraningrum, S.T., M.B.A., M.Si sebagai dosen pembimbing peneliti yang telah bersedia membimbing peneliti dari awal penelitian ini dilakukan hingga akhir.

\section{Daftar Pustaka}

Devito, J. A. (2013). Interpersonal Communication Book, The 13th Edition. London: Pearson.

Herdiansyah, H. (2010). Metode Penelitian Kualitatif untuk Ilmu - ilmu Sosial. Jakarta: 
Salemba Humanika.

Hasil wawancara bersama Key Informan Dewi Sartika Sari, 15 Mei 2019.

Hasil wawancara bersama Key Informan Heni Mulyati, 15 Mei 2019.

Https://www.facebook.com/MafindoID/ (diakses pada tanggal 14 Juli 2019 pukul 16.50 WIB).

KBBI Daring. Retrieved Februari 23, 2019, pukul 19.00 WIB from Https://kbbi.kemdikbud.go.id/entri/hoaks.

Mafindo. About. Retrieved Maret 8, 2019, pukul 19.00 WIB from Https://www.Mafindo.or.id/about/

Masyarakat Telematika Indonesia. (2017). Hasil Survey Wabah Hoax Nasional 2017. Retrieved Maret 8, 2019 pukul 19.30 WIB from Https://mastel.id/infografishasil-survey-mastel-tentang-wabah-hoax-nasional/.

Maulana, H., \& Gumelar, G. (2013). Psikologi Komunikasi dan Persuasi. Jakarta: Akademia.

McQuail, \& Dennis. (2012). Teori Komunikasi Massa (Edisi 6.). Jakarta: Salemba Humanika.

Moleong, L. J. (2012). Metode Penelitian Kualitatif Edisi Revisi. Bandung: PT. Remaja Rosdakarya.

Onong U, E. (2004). Dinamika Komunikasi. Bandung: PT Remaja Rosdakarya.

Ruslan, R. (2013). Kiat dan Strategi Kampanye Public Relations (7 ed.). Jakarta: Rajawali Pers.

Venus, A. (2004). Manajemen Kampanye: Panduan Teoritis dan Praktis Dalam Mengefektifkan Kampanye Komunikasi. Bandung: Simbiosa Rekatama Media. 